\section{Investigating the paranormal}

SIR-In his Commentary on "Investigating the Paranormal" (Nature 320, 119; 1986) David Marks raises important issues about the problems of studying claims in areas where strong beliefs may be involved. With regard to parapsychology, however, his analysis (and that of many others quoted by him) appears to suffer from a lack of knowledge of the more process-oriented, systematic research that characterizes much present-day parapsychology. He claims that parapsychology is functioning without any theoretical bases, without any idea of what variables are relevant, in such a way that "every new investigator must start afresh, as though he or she is the first worker in the field". Yet much research in parapsychology explores the effect of experimental manipulations, as independent variables, upon measures of $p$ si scoring as dependent variables. To appreciate this, one must be familiar with the details of original research reports. There are areas of research with partial replicability, that cannot yet be dismissed as "abortive leads"; current research does attempt to build upon them, as is evident from reading the introductory and discussion sections of research reports.

In his surveying of the value of the experimental research, Marks has relied upon two surveys of portions of that work, one by Akers and one by Hyman ${ }^{2}$ Both surveys conclude that parapsychological studies have many methodological flaws. I agree that much of the work has been flawed, but there has been considerable debate about the extent of such flaws. Marks, for instance, has ignored a fortypage response to Hyman's article by Honorton $^{3}$ which appeared in the same journal issue. The debate over specifics continues, and doubtless will for some time.

As Marks notes in his article, both John Beloff and I acknowledge that there has never been a perfect parapsychological experiment. What he does not explain, however, is that we argue that in areas studying extremely complex systems, as in the social sciences, it may be impossible to design, conduct and report a "perfect" study. In my article, I list several groups of counterhypotheses to any given study which, by their very nature, are difficult if not impossible to falsify, such as experimenter fraud or improper description of procedure. Rather, I argued, it is better to evaluate parapsychology by focusing on groups of studies that appear to find consistent relationships between a measure of psychic functioning and some other variable; that such studies would provide more relevant evidence than studies merely finding simple deviations from baseline.
I did not advocate examining "groups of studies which, although individually flawed reveal the undeniable presence of psi", nor did I advocate considering badly controlled experiments. As near as I can tell, Marks and I would agree that science progresses in its understanding by exploring functional relationships rather than merely documenting anomaly.

Lest 1 be misconstrued, certainly I agree that much of what has been done in parapsychology leaves something to be desired. Mistakes have been made, strong claims have been made by enthusiastic advocates, and theory construction has often been vague. Marks makes many good points about how advocates can be misled. But it is a mistake to assume that all who are willing to adopt the working hypothesis that there are new means of exchange between organism and environment are committed to a metaphysical belief system of some sort. If we are to improve our understanding of the phenomena explored by parapsychology, it will probably be through a more integrative approach, with more thorough evaluation of past work and better design of new research. An important component of such an integrative parapsychology would be the development of far more effective models for the strategies by which observers throughout the continuum of advocacy can be deceived by themselves and others about the nature of what they observe, perhaps along lines currently being developed by this writer ${ }^{5}$.

\section{Strathalmond Green,}

\section{Edinburgh EH4 8AQ, UK}

1. Akers, C. in Advances in Parapsychological Research Vol. 4 (ed. Krippner, S.) 112-164 (McFarland. Jefferson. North Carolina, 1984).

Hyman. R. J. Parapsychol. 49,3-49 (1985)

Honorton. C.J. Parapsychol 49, 51-91 (1985)

Morris, R.L.J. Am. Soc psychical Res. 74, 425-443(1980)

. Morris, R.L. in Foundations of Parapsychology (eds. Edge

H. . Morris. R.. Palmer, J., \& Rush. J.) 70-110 (Routledge \& Kegan Paul, London. 1986)

SIR-I should like to expose Marks's misleading simplification in the section of his paper on the paranormal headed "Coincidences"

Marks refers to Arthur Koestler and L.E. Rhine ${ }^{3}$ as publishing cases easily subsumed under the heading of coincidence. However, Koestler, for all his services to psychical research, did not investigate cases and neither, strictly speaking, did Rhine, who simply scanned for recurring features in reports that correspondents sent her. With the exception of one of Rhine's cases, those published by her and Koestler may indeed be interpreted as "simple coincidences". Other cases cannot be so readily explained.

The Society for Psychical Research gave attention to possibilities of coincidence from its earliest studies of apparitions in the late nineteenth century. This explanation may be appropriate for many ex- periences that laymen attribute to a paranormal process. They sometimes claim that a dream or hallucination of a fairly ordinary type has a paranormal link with a contemporaneous or future event that corresponds in a general way with the dream or hallucination. However, the events concerned in other cases are not ordinary, recurring ones, but unique events. A man dies only once in his lifetime, and if another person at a distance becomes aware of unusual details in his manner of dying at the time it occurs. something more than coincidence must be in play.

Consider the case of Mrs Agnes Paquet, who had a vision of her brother falling overboard when his foot got caught in a tow-rope on a tugboat (almost) at the time the brother actually drowned in this manner. Her vision included details of her brother's clothing, such as that his pants legs were rolled up so that, as he went overboard, she could "see" their white lining. She was approximately 50 miles away when she had her vision of the accident to which it corresponded. She told her husband about her vision before learning of her brother's death by telegram. and he corroborated this. The event was unique and so was the perception".

Students of paranormal phenomena. from Dr Johnson in the eighteenth century? to Henri Bergson in the twentieth have emphasized that when details of unique events are correctly communicated over long distances without the normal sensory channels we should not dismiss such experiences as coincidences.

Many cases, perhaps hundreds, like Mrs Paquet's have been published. Why should we not continue to study them?

IAN STEVENSON

Department of Behavioral Medicine and

Psychiatry,

Box 152, Medical Center,

University of Virginia,

Charlottesville, Virginia 22908, USA

Marks, D.F. Namre 320, 119-124 (1986)

2. Koestler. A. The Roots of Coincidence (Hutchinson, Lon don. 1972).

Rhine. L.E. J Parapsychol. 15. 16+191 (1951)

t. Gurney. E.. Mvers. F.W.H. \& Podmore. F. Phantasms of the Liring (Trübner. London. 1986).

Sidewick. H. \& Committee Proc. Soc: psichical Res. 10. $35-432(1894)$

Sidgwick

F Proc: Soc pschical Res. 7, 30-49(1981)

Boswell. J. The Life of Sammel Jolunson 246 (Modern Lib. rary. New York. 1931).

8. Bergson. H. Proc. Soc psychical Res. 26, 462-479 (1913)

\section{Trouble on the farm}

SIR-"Cheap and nasty trees" (leading article Nature 322, 195; 1986) are the backbone of Scandinavian forestry. To suggest that they are not good enough for Britain is a striking example of how widespread is that British malaise responsible for so many of our current problems.

Llangunville, Llanrothal,

E. NiCHOLL 